\title{
Anaplastic, T-Cell, Non-Hodgkin's Lymphoma Presenting with Haematuria
}

\author{
C. Blick ${ }^{1, \star}$, S. Abdelhadi ${ }^{1}$, D. Bailey ${ }^{2}$, and A. Muneer ${ }^{1}$ \\ ${ }^{1}$ Department of Urology, ${ }^{2}$ Department of Pathology, Wycombe General Hospital, \\ Buckinghamshire NHS Trust \\ E-mail: cblick@doctors.org.uk
}

Received September 13, 2007; Revised March 11, 2008; Accepted March 14, 2008; Published March 25, 2008

\begin{abstract}
Non-Hodgkin's lymphoma (NHL) represents about $3 \%$ of new cancer cases[1]. Bladder involvement has been found in approximately $3-13 \%$ of NHL patients when studied at postmortem[2]. Although accounting for only $0.2 \%$ of all primary bladder tumours, the majority of bladder lymphomas are B-cell lymphomas. T-cell lymphoma of the bladder is incredibly rare. We describe a case of anaplastic, T-cell lymphoma presenting with haematuria and loin pain, with unilateral upper tract obstruction.
\end{abstract}

KEYWORDS: bladder, lymphoma, anaplastic large-cell lymphoma, haematuria

\section{CASE SUMMARY}

We describe the case of a 26-year-old man with an unusual presentation of lymphoma. He was referred to the urology department by his general practitioner with a 3-month history of back pain, macroscopic haematuria, weight loss, and night sweats. He was of Pakistani origin and as a child had received a full course of antituberculous treatment.

Initial investigations consisted of a renal tract ultrasound and intravenous pyelogram. The ultrasound scan revealed a thick-walled bladder with a heterogeneous mass arising from the bladder neck and prostate. A prominent left renal pelvis was also noted and a standing column of contrast in the left ureter to the vesicoureteric junction was seen at $1.5 \mathrm{~h}$ postcontrast. Rigid cystoscopy revealed a large, granulomatous, solid mass involving the prostate, bladder neck, trigone, and left ureteric orifice. The putative diagnosis at that time was tuberculosis (TB) of the bladder. The tumour was resected and histopathology revealed an aggressive, pleomorphic tumour. Immunohistochemistry was positive for ALK-1 (cytoplasmic and nuclear pattern), CD30, CD3, and CD4. Proliferation index with MIB-1 was high at $60 \%$ (Figs. 1-5). There were no stains for CD2, CD7, CD8, CD10, CD34, TdT, and CD79. A diagnosis of an ALK-positive, anaplastic, T-cell, non-Hodgkin's lymphoma was made. No genetic or molecular genetic studies were performed or T-cell clonality demonstrated. A staging CT scan showed extensive disease, with thoracic, axillary, retrocardiac, mediastinal, retroperitoneal, mesenteric, and pelvic lymphadenopathy. There were also multiple pulmonary nodules and a large lytic defect in the left innominate bone. Incidentally, multiple calcifications in his spleen and liver consistent with prior TB were also seen. He was commenced on the CHOP regime of chemotherapy (cyclophosphamide, doxorubicin, vincristine, and prednisone). 


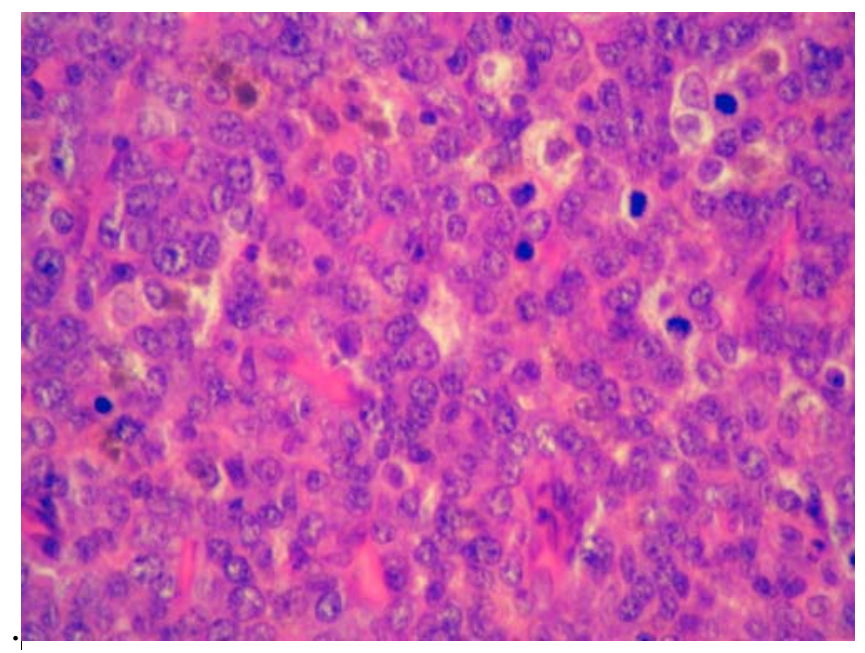

FIGURE 1. High power H\&E of tumour.

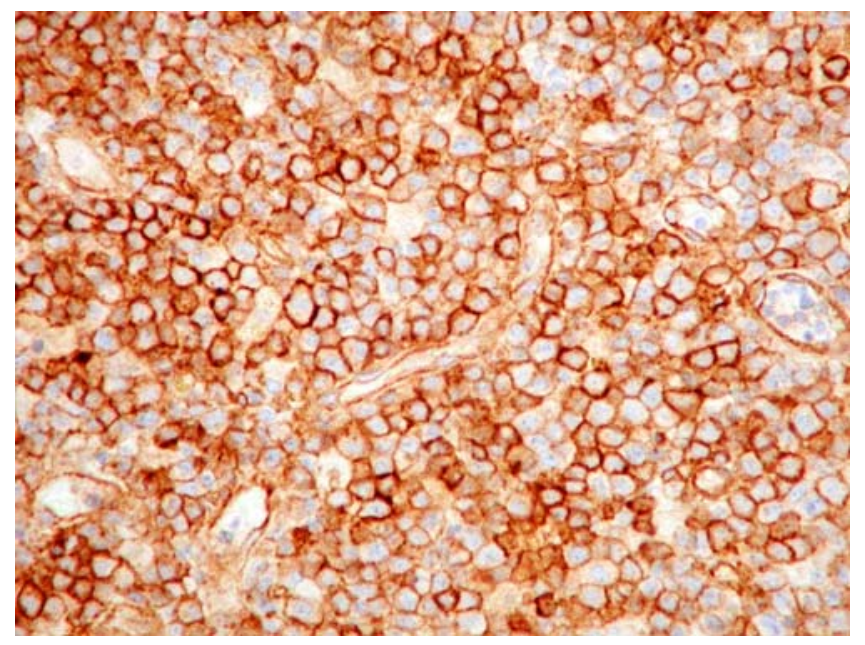

FIGURE 2. CD30 positivity.

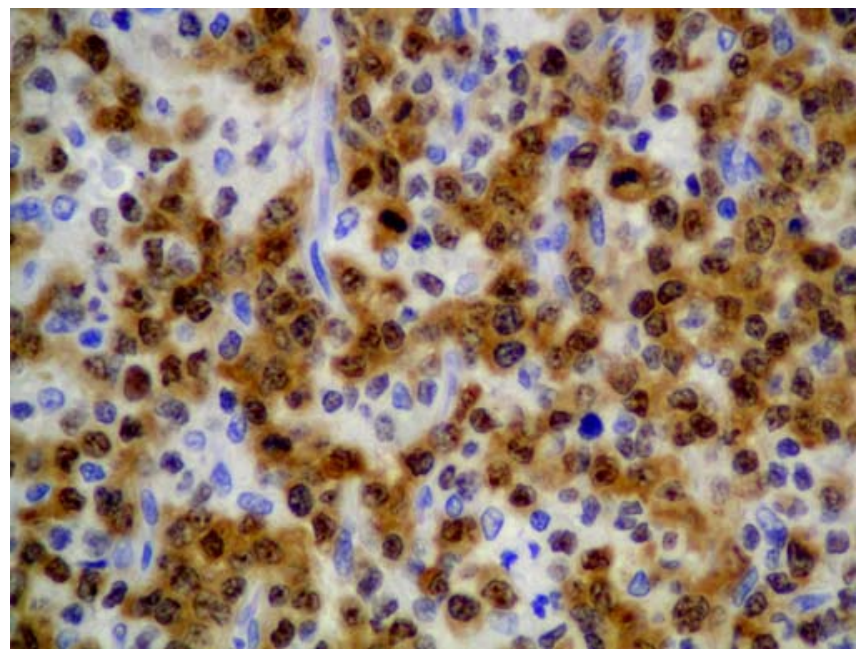

FIGURE 3. Alk 1. 


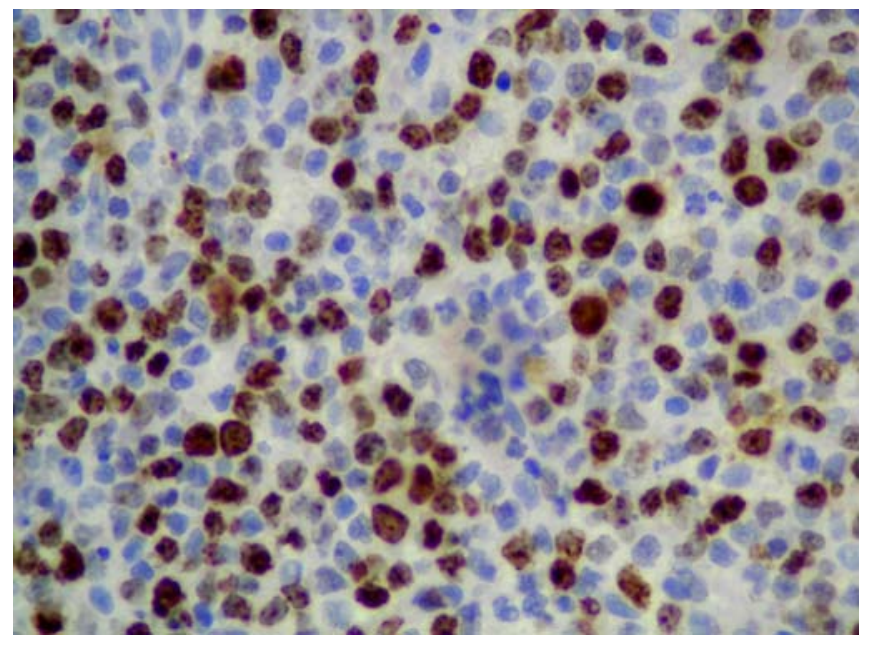

FIGURE 4. mib 1.

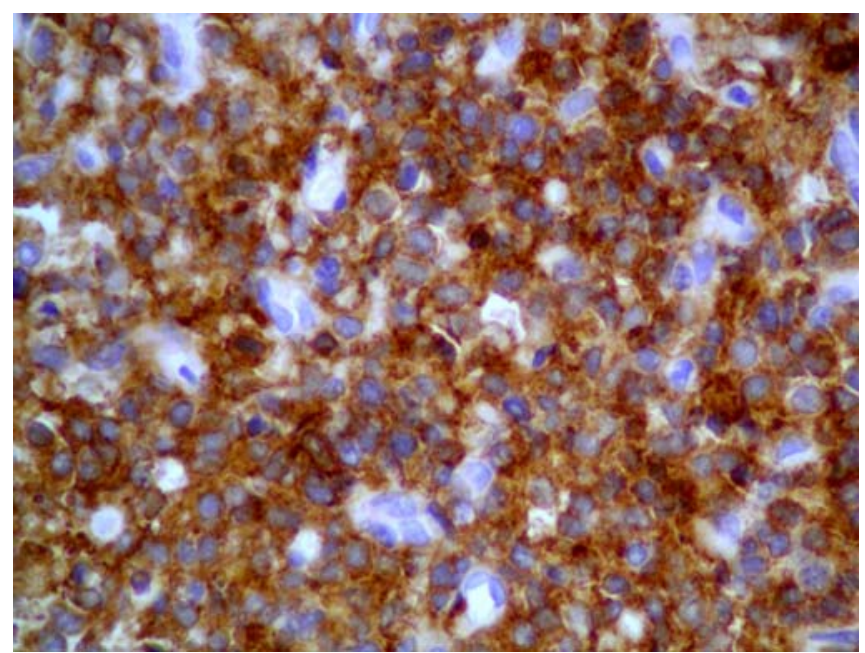

FIGURE 5. CD4.

\section{DISCUSSION}

Urinary tract involvement in NHL is well documented, occurring in between 3 and 13\% of NHL patients[3,4]. Bladder lymphomas are usually secondary deposits and can often be the presenting lesion of a previously unrecognised diffuse lymphomatous process[2]. Primary lymphoma of the bladder is very rare and nearly always B cell in origin[5]. There are only two reports of Hodgkin's lymphoma of the urinary bladder. The majority of bladder lymphomas are marginal zone lymphomas of mucosa-associated lymphoid tissue[5]. ALCL (anaplastic large cell lymphoma) involving the bladder is very unusual and there has only been one previous case presenting with haematuria[9]. ALCL is usually associated with cutaneous and extranodal involvement, young age at presentation, male predominance, and is not associated with urinary tract symptoms. Primary systemic ALCL is typically in an advanced stage at presentation and the disease is rapidly progressive. These patients have an increased incidence of bone marrow involvement (30\%) and extranodal involvement, including skin (21\%), bone (17\%), soft tissues (17\%), lung (11\%), and liver (8\%). Systemic symptoms are observed in $75 \%$ of patients, with fever the most common symptom. The malignant cells stain positive for the CD30 antigen, a very sensitive but 
nonspecific test result that is also positive in other lymphomas, including Hodgkin's disease( CD3 and alk positivity in this case excludes Hodgkin's). Most cases exhibit either T-cell or null phenotype, with frequent CD3 expression, cytotoxic protein expression, clonal T-cell receptor gene rearrangements by polymerase chain reaction (PCR), and lack of B-cell-associated markers. The primary systemic form, unlike the primary cutaneous form, generally stains positive for EMA and usually displays the $t(2 ; 5)$ translocation and the chimeric p80 protein with PCR and antibody studies[7]. The precise route that these tumours appear in the bladder is uncertain. The presence of lymphomas in the bladder may be related to either intrinsic foci or haematogenous spread causing tumour with multiple foci[6,8]. This case is unique, as T-cell lymphoma presenting with haematuria and upper tract obstruction has not previously been described. Lymphoma should be considered under differential diagnosis of bladder tumours, particularly if there are systemic symptoms or atypical features concerning the patient demographics or clinical history.

\section{REFERENCES}

1. Racioppi, M., Deliu-Victor, M., Sica, S., Pizzo, M., Destito, A., Alcini, A., and Alcini, E. (1996) Non-Hodgkin’s lymphoma: a case report of a secondary bladder involvement. Scand. J. Urol. Nephrol. 30, 429-431.

2. Melekos, M.D., Matsouka, P., Fokeafs, E., Pantazacos, A., and Repanti, M. (1992) Primary non-Hodgkin's lymphoma of the urinary bladder. Eur. Urol. 21, 85-88.

3. Oh, K.C. and Zang, D.Y. (2003) Primary non-Hodgkin's lymphoma of the bladder with bone marrow involvement. Korean J. Intern. Med. 18(1), 40-44.

4. Mourad, W., Radwi, A., Khalil, S., Peracha, A., and Ezzat, A. (1998) Primary T-cell lymphoma of the urinary bladder. Am. J. Surg. Pathol. 22(3), 373-377.

5. Kempton, C.L. et al. (1997) Malignant lymphoma of the bladder: evidence from 36 cases that low-grade lymphoma of the MALT-type is the most common primary bladder lymphoma. Am. J. Surg. Pathol. 21(11), 1324-1333.

6. Weimar, G., Culp, G.A., Loening, S., and Narayana, A. (1981) Uro-genital involvement by malignant lymphomas. $J$. Urol. 125, 230-231.

7. Quinn, A., Flanigan, R., Sienko, A., and Wojcik, E. (2004) Cytologic features of recurrent lymphoma involving the urinary bladder. Diagn. Cytopathol. 31(3), 185-188.

8. Guthman, D., Malek, R., Chapman, W., and Farrow, G. (1990) Primary malignant lymphoma of the bladder. J. Urol. 144, 1367-1369.

9. $\quad$ Murphy, A., O’Neill, P., O’Brien, F., Enright, H., Jeffers, M., Thornhill, J., and Loftus, B. (2005) Anaplastic large cell lymphoma: a unique presentation with urinary bladder involvement. Int. J. Surg. Pathol. 13(4), 369-373.

\section{This article should be cited as follows:}

Blick, C., Abdelhadi, S., Bailey, D., and Muneer, A. (2008) Anaplastic, T-cell, non-Hodgkin’s lymphoma presenting with haematuria. TheScientificWorldJOURNAL: TSW Urology 8, 342-345. DOI 10.1100/tsw.2008.52. 


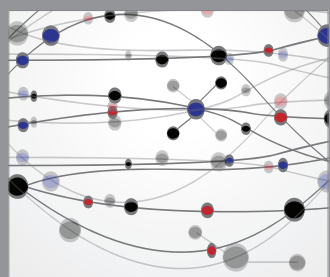

The Scientific World Journal
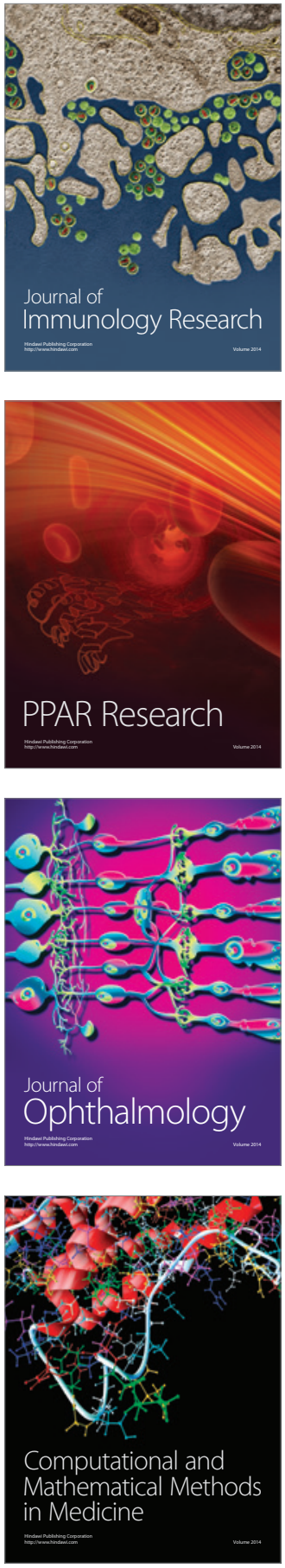

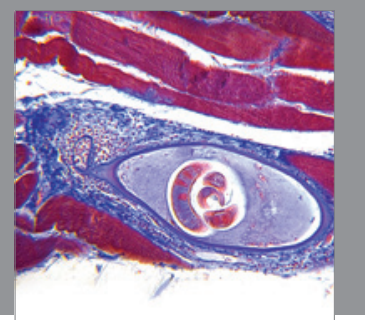

Gastroenterology

Research and Practice
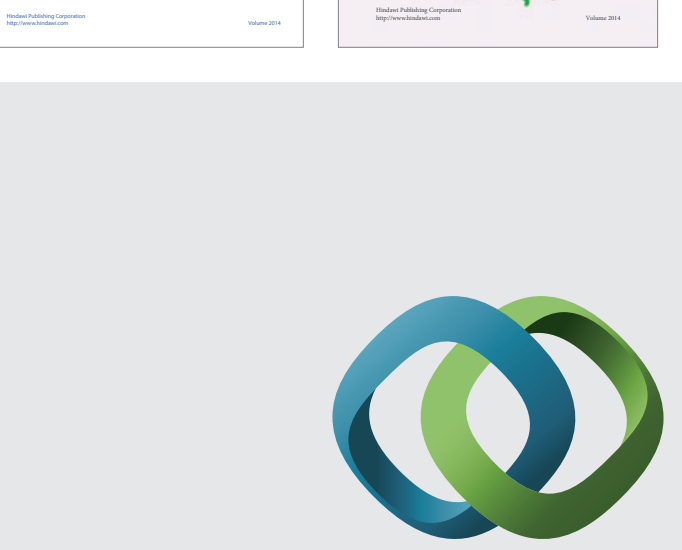

\section{Hindawi}

Submit your manuscripts at

http://www.hindawi.com
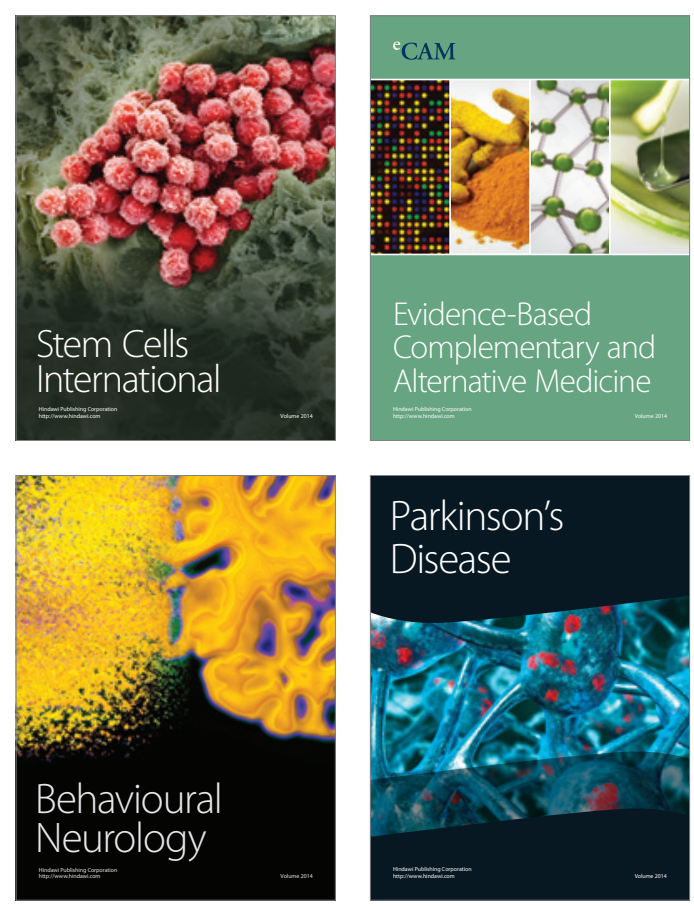

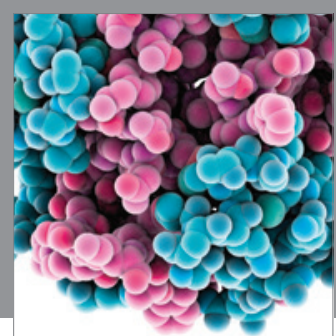

Journal of
Diabetes Research



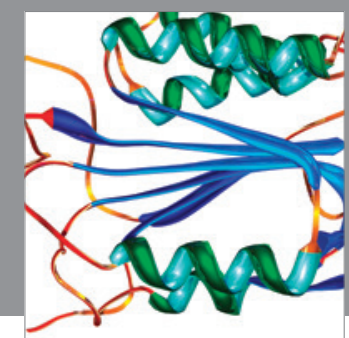

Disease Markers
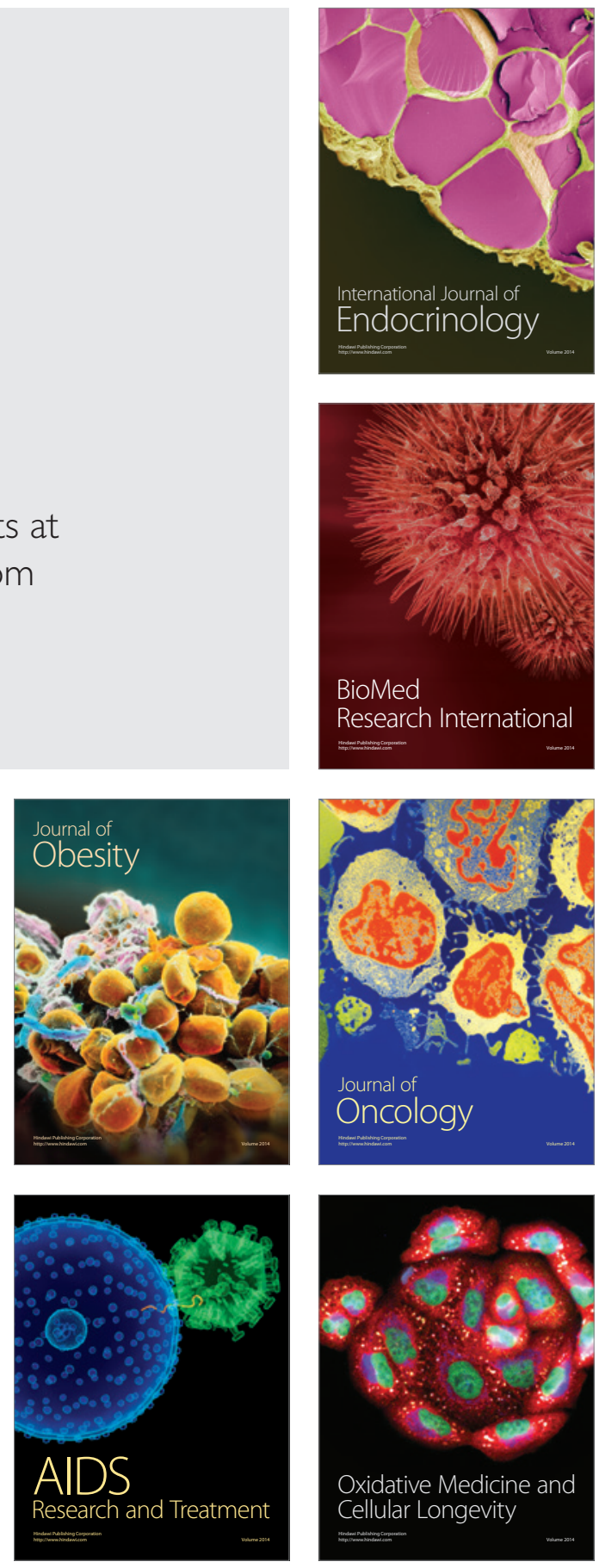